\title{
A lírica menor: Por uma Teoria da Literatura das Literaturas Africanas de Língua Portuguesa
}

\author{
Lívia Natália Santos*
}

\section{Resumo:}

O centramento das questões relativas aos paradigmas da Teoria da Literatura nos textos produzidos num determinado contexto ético-estético muitas vezes inviabiliza a compreensão das produções literárias que se produzem fora do eixo eurocêntrico. A Teoria da Literatura enquanto campo disciplinar tende, pela construção de seus critérios estéticos, a deixar escapar a recente escrita literária, principalmente aquela emergente das periferias. Através da análise de alguns poemas de Ana Paula Tavares, poeta angolana, este artigo buscará discutir os limites da Teoria da Lírica diante da produção literária pós-colonial.

\section{Palavras-chave:}

Teoria da Lírica, Literatura angolana, Pós-colonialismo, Ana Paula Tavares

É que as margens de um livro jamais são nítidas nem rigorosamente determinadas: além do título, das primeiras linhas e do ponto final, além de sua configuração interna e da forma que lhe dá autonomia, ele está preso em um sistema de remissões a outros livros, outros textos, outras frases: nó em uma rede. A Arqueologia do Saber, Michel Foucault

\footnotetext{
* Doutora em Teorias e Crítica da Literatura e da Cultura pela UFBA. Professora da Universidade Estadual de Santa Cruz, Ilhéus, Bahia.
} 
A lírica é o espaço, por excelência, da recordação. Organizando-se num tempo de estrutura circular, expulsando-se do espaço linear e causalítico no qual se organizam os gêneros trágico e épico, a lírica canta a teleologia perdida. $\mathrm{Na}$ emaranhada teia na qual se constroem e consomem os afetos, o início se instala num passado permanentemente reencenado no presente. $O$ sentimento que atravessa a lírica, dilacerado, espraia-se por cada palavra disseminando a emoção poética que, posicionando o texto para além da rotina emaranhada dos dias e noites, instala-a numa temporalidade outra, apartada do cotidiano macerante. É neste contexto - pretensamente a-contextual - que o poeta instala o seu afeto. Sendo o afeto o centro da poesia e a cena de sua inadequação e insatisfação em relação ao mundo o grande assunto sobre o qual se versa (seja no olhar não retribuído, na perda, ausência, saudade ou solidão), a lírica é pessoal e intransferível, é a fala que se ergue caudalosa de um rio profundo que é a psique humana.

No entanto, a crença de que a psique se constrói numa pretensa interioridade pura (cf. DERRIDA, 2002, p. 230) vem sendo reconfigurada nos últimos anos com o aporte teórico dos Estudos de Cultura, que se dedicam a investigar as conseqüências das relações entre o sujeito e o mundo na dimensão prática de sua vida cotidiana. Para além da crença da construção da subjetividade exclusivamente no contexto das relações estabelecidas no núcleo familiar mínimo - pai/mãe - os Estudos de Cultura tendem a provocar uma leitura mais horizontalizada desta construção compreendendo a formação da psique a partir das interações que o sujeito desenvolve no/com o mundo, analisando as conseqüências destas no seu corpo ideológico (FOUCAULT, 1979, p. 146). As formas de relacionamento do sujeito com o mundo assim como o espaço político que este ocupa se mostram refletidas nas práticas e resultados da interdição e permissão de sua auto-representação social e política, nas construções e desconstruções de estereótipos (associadas com a convivência com estes) e, finalmente, nos reflexos destes estabelecimentos ideológicos sobre o seu corpo físico e discursivo.

No espaço da construção literária, e, mais que nos demais gêneros, na lírica, as relações do sujeito com o mundo devem ser mediadas por demandas geradas no seu "universo interior", este arquétipo de escrita poética, no entanto, não dá conta, por exemplo, da escrita poética construída por sujeitos que sentem o contexto político e social como pressões poderosas na formação de sua subjetividade e vivenciam as graves conseqüências destas em seu corpo, inserção política, cultural e na formação de seu lugar de fala. A poesia não está 
infensa às demandas sociais, ideológicas, políticas e subjetivas que dominam o cenário da pós-modernidade, sendo assim, os mergulhos subjetivos se relativizam e passam a interagir com uma ação e interesse direto com o universo circundante. Comportando-se assim, o texto poético escapa a um determinado cânone estético.

A força do estabelecimento do espaço canônico não se encontra, como se faz crer, apenas nas obras que para eles são escolhidas em decorrência de serem elas portadoras de um determinado conteúdo. Pelo contrário, isto que se pensa como sendo a "interioridade" do texto literário é apenas uma simulação de uma interioridade. O texto é pura exterioridade, pura superfície, por mais que esteja submisso à leitura que, imagina-se, adentra-se nele expulsando o seu sentido "para fora", é importante, neste momento, caminhar pelas palavras de Michel Foucault, o que temos desde o pensamento nietzschiano é a "reviravolta da profundidade, a descoberta de que a profundidade não passava de um jogo e de uma dobra na superfície" (FOUCAULT, 2005, p. 44).

Assim, a interioridade, que produz uma determinada malha e/ou postura interpretativa pode ser pensada como um movimento absolutamente ilusório de se poder abrir a palavra que, como um fruto, será rasgado dele emergindo, vigorosa, sua semente. Entretanto a palavra, como qualquer signo, sempre estará fechada, a abertura é um acontecimento absolutamente relativo e circunstancial e o seu sentido uma produção derivada de uma ação de corte, de uma decisão de leitura (DERRIDA, 2005, p. 17).

A decisão de leitura é um conceito que pode se articular com a noção de interpretação, no sentido de compreender todo texto, principalmente o literário, como polissêmico e farto campo de produção e disseminação de sentidos. Entretanto, o espaço de leitura é, e precisa ser para que ela se revista de um espaço de "verdade", um lugar onde morrem estrelas. Explico: toda decisão de leitura, toda interpretação é, antes de tudo, o necessário e temporário fechamento numa leitura e o silenciamento de outras interpretações possíveis. Esta é a interioridade máxima do texto, a sua interpretação que, paradoxalmente, não resvala para além da superfície.

Entretanto, no momento do trabalho de estabelecimento do cânone há uma perigosa organização política, uma vez que, estejamos certos, os critérios estéticos derivam de um padrão de aceitabilidade ideológica e este vem mascarado pela simulação de um determinado padrão de criatividade, de invenção que alimenta a idéia de que há, em determinado textos, uma organização de linguagem que provoca (e merece) uma atenção especial do 
leitor. O cânone (PADILHA, 2002, p. 163), enquanto estratégia de fechamento, exclusão e controle que é, estabelece uma mítica do texto artístico como sendo um corpo controlado por ciclos e manias muito próprios e exclusivos. E é justamente esta idéia de diferença que produz as hierarquias que regulam, por exemplo, a intensidade de leitura, publicação e circulação dos textos dos "grandes" e dos "pequenos" escritores.

"É preciso também que nos inquietemos diante de certos recortes ou agrupamentos que já nos são familiares" (FOUCAULT, 2000, p. 24), quando articulamos esta reflexão de Foucault com a idéia aqui desenvolvida da intencionalidade ideológica do estabelecimento do cânone, compreendemos que, diante dele, há que se ter uma postura iconoclasta. A força desta mão não está em destruir definitivamente o cânone, silenciando-o. Pelo contrário, cabe a esta mão, metonímia de um pensador, sacudir, com força, a quietude com que aceitamos esta cadeia política e denunciar, pelo abalo produzido, as fissuras de onde surgirão os questionamentos. Assim, estaremos diante das idéias de tradição, herança, influência, beleza, evolução, bases sobre as quais se sustenta o cânone, menos inocentes e mais cientes do quanto têm, todas elas, de artifício.

Neste contexto, a produção de escrita poética nos países de Língua Portuguesa do continente africano, primordialmente, como é o caso de interesse aqui, em Angola, precisa ultrapassar algumas barreiras muito fortes.

A primeira delas diz respeito à função social que o texto literário adquire no contexto angolano; para tanto, cabe aqui uma pequena digressão. Em 1926, Salazar, então ministro, de Portugal impõe a prática da política assimilacionista. A assimilação obriga os africanos a abandonar os seus usos e costumes tradicionais; adotar a religião católica; falar e ser alfabetizado em português e submeter-se à lógica econômica européia (SANTOS, 1997, p. 61). Este processo de europeização, comumente acessível às famílias angolanas de classe média, abre a possibilidade para que muitos intelectuais pudessem estudar em Lisboa, principalmente, unindo-se em grupos de escritores fazendo com que a Casa dos Estudantes do Império (CEI) fosse um grande pólo disseminador de idéias e um centro de onde nasceram o vigor da luta pela liberdade mediada pela escrita literária. Uma vez que o espaço para a divulgação de uma história oficial ou, ainda, de reivindicação por um lugar reconhecido de fala no discurso político para a auto-representação e auto-gestão era, naquele momento, inviável, é a literatura que escreverá a história outra de Angola com o lema do movimento anti-colonialista: "Vamos Descobrir Angola". 
O lema traz, consigo, uma idéia que se inscreve na dobra da ambigüidade. Como "descobrir" Angola? Já não está ela aí, evidente e viva? Que Angola é esta que se deseja descobrir? A resposta a estas indagações talvez se guarde mais na força do verbo "descobrir" que provoca a idéia de que Angola precisa ser desvelada, revelada e descoberta no sentido mesmo de retirarem-se dela todos os cobertores que abafam a sua respiração e inviabilizam a sua vida, deixar respirar o seu povo exilado em seu próprio território. o que a colonização abala é uma das rotas fundamentais sobre a qual circula a noção, tão importante em África, de pertença. A noção de pertença, para além da idéia ocidentalizada de nação como comunidade supra-territorial que se une pela estrada da língua, é o acesso livre ao uso e produção de bens simbólicos que, obviamente, passam pela língua - e lembremos que, em África elas são muitas e numerosas - mas que também se resguardam nos ritos, mitos e modos outros de inscrição de identificações no perfil subjetivo.

Neste contexto, a literatura toma para si uma função. Comumente pensada como sendo o fim sem fim, sobre o texto literário deposita-se a força de deslocamento do poder opressor e de abalo dos lugares marcados.

Nesta missão, o gênero literário de luta, por excelência, é a prosa, preferencialmente o romance. Aqui temos a segunda barreira à qual nos referíamos, ao próprio uso do gênero literário poesia. Pensada como escrita de cunho meramente subjetivo, e, portanto, interior, a poesia seria arma fraca de luta, vez que não engendra no seu corpo o claro cenário do sofrimento e das batalhas. Esta questão liga-se à idéia ocidentalizada de que a poesia só se constrói, simultaneamente, pelo afastamento doloroso e fusão narcísica entre o sujeito e o mundo, e, a literatura angolana de luta anti-colonial e de estratégias de construção de nacionalidade no contexto pós-colonial, precisa mais do mundo do que do sujeito. O mundo, pensado como a Angola em descoberta ou em reconstrução, é o cenário que precisa ser destacado e representado, tão importante quanto o cotidiano dos camaradas de armas e de trincheiras, é a descrição, o desenho mais claro quanto possível dos espaços de batalha, da Angola violentada, depauperada e desolada e isto, para muitos, apenas a narrativa poderia trazer. A narrativa é, assim, o espaço da pura lembrança. Se retornarmos à teoria hegeliana da epopéia - da qual deriva uma dada forma de narrativa, primordialmente aquela que se dedica a narrar a história de um povo - o gesto de contar uma determinada história toma ares pedagógicos, na medida em que um narrador exemplar toma para si a travessia de um herói, também exemplar, e a coloca em circulação para uma audiência submissa e 
atenta. O herói, mais que uma personalidade individual, é uma metáfora, uma representante da totalidade do povo.

A lembrança ativada pela narrativa, diferente da recordação lírica, é a reencenação constante de um fato fechado, de uma história pensada como um dado acabado que deve ser repetida sempre pelo mesmo caminho, atravessando as mesmas estratégias de narrativas a fim de, pela repetição, cimentar uma visão unificadora - e quase histórica - de povo.

Já a recordação lírica é sempre uma circularidade, uma repetição na diferença, obedecendo ao sentido derridiano de différ (DERRIDA, 2002, p. 200) instala-se um sistemático adiamento, o que quer dizer que o sentimento que a lírica traduz não repete o momento anterior que serviu de inspiração para a escrita do texto, o sentido é outro, ao ouvir a história pela voz absolutamente parcial do sujeito lírico, temos contato com uma outra história, mais pungente e sentimental que aquela que Ihe serviu de inspiração. A lírica, assim como a história, é a cena do necessário esquecimento, diria Nietzsche.

Há, entretanto, aquilo que escolhi chamar neste texto de lírica menor, a saber, a escrita angolana de autoria feminina. As angolanas, a exemplo de Alda Lara (1930-1962), escreveram textos literários no contexto colonial e estes, comumente, para além de qualquer marca de gênero, estendiam, como bandeira, a libertação. Desta forma, o vigoroso apagamento na cena textual do rastro de uma determinada "escrita feminina" deixou, durante muito tempo, um espaço de fala vacante, uma vez que estas mulheres estavam compromissadas com uma demanda que, naquele momento, era maior: a escrita estava empenhada na função social legítima de luta anti-colonial. Se há, como afirma Foucault, estratégias de exclusão de discursos que estabelecem que: "não se tem o direito de dizer tudo, que não se pode falar de tudo em qualquer circunstância, que qualquer um, enfim, não pode falar de qualquer coisa" (FOUCAULT, 1998, p. 9), o que a poesia feminina angolana faz é subverter todas estas interdições e mais outras, uma vez que não apenas se constrói nesta forma, mas também toma, para si, como assunto, o campo subjetivo. Mas até esta subjetividade que aqui se apresenta afasta-se da visão limitada e romanceada de sujeito lírico e finda por inscrever-se num espaço híbrido, onde se apresentam as questões de dimensão íntima deste sujeito que, no entanto, é um eu-lírico marcadamente feminino e africano, assim, ali onde cessariam as questões ideológicas, elas tomam nova força uma vez que o sujeito que ali se apresenta é marcado por dois poderosos lugares de exclusão: mulher e africana. 
Quando, já no período pós-colonial, começam a surgir novas vozes elas vêm carregadas de outras funções sociais, articulam e ensejam, na cena de seus textos, outras lacunas de fala, outras demandas de representação. E é neste horizonte que se inscreve a escrita de Ana Paula Tavares. Nascida em Lubango, Huíla, Sul de Angola, em 1952, Ana Paula Tavares é historiadora, tendo obtido o grau de Mestre em Literaturas Africanas de Língua Portuguesa pela Faculdade de Letras da Universidade de Lisboa. A sua formação em história, quando articulada com a escrita poética, resulta numa tendência muito contemporânea que é a da desconfiança diante da fala da história e a necessidade de trilhar percursos diferentes de análise e narração desta. Assim, a atuação da poeta em várias entidades ligadas a literaturas e histórias da África ressoa na sua escrita poética quando da reavaliação de sua própria travessia histórica, e, de forma arquetípica, mas, sempre ambivalente e aberta à diferença, a travessia da mulher africana. Nesta empresa, Ana Paula Tavares publicou vários livros de poesia - Ritos de Passagem (1985), O Lago da Lua (1999), Dizes-me Coisas Amargas como os Frutos (2001), Ex-Votos (2003), Manual para os Amantes Desesperados (2007) e, em prosa, O Sangue da Buganvília (1998) e A Cabeça de Salomé (2004).

Assim ela contextualiza a sua prática poética:

(...) Tive portanto o privilégio de ter nascido ali, de ter uma avó negra do Kuanhama, e uma avó branca de Castelo Branco, que me deu esta fala, a outra fala. Do que é que aquelas duas mulheres à noite falavam? Havia um ruído de fundo de que eu fui à procura. E por grande sorte minha descobri que já no século XIX, alguns missionários tinham perseguido esse ruído. Bem ou mal, tinham fixado formas desse ruído em narrativas, em poemas, mitos de fundação, epopeias... E assim eu pude ler - sabendo que havia ali uma traição - mas pude ler a memória daqueles povos. E pensei: Este é o meu caminho. Se eu conseguir fazer alguma coisa, é por aqui que eu vou. Não faço poemas etnográficos, eu faço ficção. Eu não vejo a minha terra como Sembene Ousmane, o grande realizador senegalês, dizia a Jean Rouch, o homem grande do outro cinema: «Tu filmas os africanos como gafanhotos, e só ficamos em pé de igualdade quando um dia eu conseguir filmar os europeus como gafanhotos». Eu não vejo a minha terra, estas mulheres, estes homens, estes pastores, como gafanhotos. Eu e a minha terra não nos separamos.

Não uso todo este material a que felizmente tive acesso como uma fonte, onde eu vou debicar aqui ou ali. Eu tento incorporar muito deste material e saber como foi... Eu que não fui uma mulher que passei pela iniciação, eu que sou uma mulher que só falo línguas imperiais... mas tenho ouvido o som de outras línguas, e portanto, eu não faço cópias: trabalho, canibalizo e devoro como muitos outros africanos fizeram. Esse é o trabalho 
que tento fazer: a incorporação de vários patrimónios, e se o meu olhar para ver o mundo é aquela terra, aquele espaço, eu também não estou cega ao resto do mundo. Leio a poesia do mundo e estou aberta a todas as experiências do mundo. $\mathrm{O}$ que eu procuro é não confundir as coisas, nem confundir os níveis, e trabalhar com um legado que a sorte pôs à minha disposição. (TAVARES apud RIBEIRO, 2008, p. 121)

Paula Tavares tem sua escrita marcada pela reflexão sobre o feminino a partir de um poderoso investimento na potência deslocadora e inventiva da escrita da história pela poesia. Uma vez que, segundo ela:

É muito recente este fenômeno de haver uma consciência do "eu feminino" e uma tentativa de reivindicar este espaço que ele comporta. Mas também não podemos interpretar, mesmo em relação às novas tendências, mesmo em relação às coisas que surgiram há pouco tempo, não podemos interpretar isto como uma poesia de gênero. Digamos que algumas mulheres, sobretudo a partir dos anos 80 , começaram a deslocar o centro onde o sujeito poético estava muito fincado. Então, há uma poesia que surge falando da problemática de ser mulher numa sociedade africana como a nossa. (TAVARES, 2000)

Ao se afastar de uma escrita de gênero, Tavares propõe um deslocamento, inclusive, no conhecimento eurocentrado de gênero. A defesa aqui é de uma escrita feminina no sentido de que traz, para a cena da lírica, o universo da mulher não apenas como tema, mas como opção estética, como uma espécie de gramática poética.

Representando o tempo atemporal dos ciclos femininos da lua, dos mares e dos rios que alegorizam os próprios ciclos do corpo feminino, o sangue menstrual, o aleitamento, os gozos e desejos do corpo, narrando os gestos, reações e vivências como ritos, a poesia de Ana Paula Tavares traça uma subjetividade marcada, preenchida, feminina:

Cerimônia de Passagem

"a zebra feriu-se na pedra

a pedra produziu lume"

a rapariga provou o sangue

o sangue deu fruto

a mulher semeou o campo 
o campo amadureceu o vinho

o homem bebeu o vinho

o vinho cresceu o canto

o velho começou o círculo

o círculo fechou o princípio

"a zebra feriu-se na pedra

a pedra produziu lume"

(Dizes-me coisas amargas como os frutos. Luanda, 1985)

A cena da cerimônia começa e se fecha com um mistério, este, aliás, atravessará toda a mítica e a mística africana vindo, nas religiões de matriz afro, ensejar o lugar do segredo como um espaço definitivo do poder: num terreiro nada se pergunta, se aprende. Assim, a zebra que se feriu na pedra recupera a importância do sangue nos rituais e este, como partícula metafísica do corpo feminino, como parte integrante do ciclo, se destransforma de sangue em lume, em luz. Diferente de uma leitura de matriz cristã, que apontaria para uma redenção pelo sofrimento, o sangue que brota da zebra é sangue, mas é também uma outra coisa, e esta outra coisa é a alegoria, imagem-base da cultura africana.

Este mesmo sangue com seu poder de lume converte a rapariga na mulher, numa possível referência ao sangue da menarca - primeira menstruação - ou o sangue, também iniciático, do desvirginamento ou do parto. O campo em "a mulher semeou o campo / o campo amadureceu o vinho" pode ser lido como o corpo fértil que, dentro de si, amadurece - no tempo mais certo - não a uva, mas já o vinho, elemento desorganizador de uma ordem, acesso à via imaginária, à embriaguez. Apenas aí aparece o homem, bebendo do vinho, cantando seu canto e o velho começando o círculo que, por si, acha o seu princípio. Aqui o que se vê é uma delimitação de espaços: o interno, do feminino; e o externo, que canta, que tem mãos para riscar o círculo, do masculino. Entretanto, sem a ordem interiorizada do ritual da mulher, nada poderia ser posto a circular. Nisto, a poesia representa a maneira patriarcal de divisão do trabalho: 
De um lado os homens, a quem as civilizações atribuem os trabalhos voltados para o lado do exterior, do oficial, do público, do direito, do alto, do descontínuo (...) Por exemplo, alimentar os animais, levar o rebanho ao pasto, cultivar os campos, arar a terra, semear, (...) Às mulheres competem os afazeres classificados como fazendo parte do lado interior, úmido, baixo, contínuo, por isso lhes são atribuídos todos os trabalhos domésticos, isto é, os trabalhos privados e escondidos e até mesmo invisíveis ou vergonhosos, os mais sujos, monótonos, penosos e humildes. Por exemplo: cozinhar, criar e alimentar as crianças, os animais, varrer, tecer, moer, ordenhar, transportar água, amassar o barro. (BOURDIEU, 1995, p.113)

Outra imagem que aparecerá com alguma freqüência na poesia de Paula Tavares é a da mãe. Diferente da metáfora já gasta articulada por muitos poetas dos dois lados do atlântico da África-mãe, a maternidade aqui é vivenciada pelo viés da cumplicidade, da convivência estreita de dois sujeitos submissos a um mesmo espaço subjetivo. Se a mulher não encontra em outros lugares a chance de sua escuta amorosa e atenta, é no espelhamento narcísico entre mulheres, sempre orbitando pela circularidade mãe-filha, independente de assim o serem, que formará uma cadeia de aproximações sutis e afetivas:

\section{O Cercado}

De que cor era o meu cinto de missangas, mãe feito pelas tuas mãos

e fios do teu cabelo

cortado na lua cheia

guardado do cacimbo

no cesto trançado das coisas da avó

Onde está a panela do provérbio, mãe

a das três pernas

e asa partida

que me deste antes das chuvas grandes

no dia do noivado

De que cor era a minha voz, mãe

quando anunciava a manhã junto à cascata

e descia devagarinho pelos dias

Onde está o tempo prometido p'ra viver, mãe se tudo se guarda e recolhe no tempo da espera 
p'ra lá do cercado.

(Dizes-me coisas amargas como os frutos. Luanda, 1985.)

A bela metáfora do cinto de missangas e dos cabelos - ambos fios que laçam e remetem à cena de iniciações várias, estão abrigados no cesto-útero, tecido pela avó, metáfora da ancestralidade que, em muitos lugares da África, é matriarcal. Hoje aprisionado num para cá do cercado, o eu lírico reclama sua herança materna, reivindica os elementos através dos quais poderia soerguer nova voz e força. A pergunta aflituosa do "onde" que se repete, estribilho, no corpo inteiro do poema instaura um ciclo novo, que se vivencia do espaço da ausência e da vacância.

A leitura mais atenta, logo perceberá nesta lírica menor uma capacidade absolutamente feminina - posto que feita nos escuros e úmidos, engendrada no útero e nas entranhas. Aqui, o estético é ético, o poético é político, entretanto, não falamos aqui do universo de trincheiras e de guerras exteriores e masculinas, a cena da luta que aqui se apresenta é aquela travada nos baixos e sombrios lugares onde dormem os mais poderosos silenciamentos, onde o corpo guarda para si, e fala em linguagem esquecida, a história dos menos importantes que é a sua própria história, para os que tenham ouvidos de lhes ouvir.

\section{Referências Bibliográficas:}

BOURDIEU, Pierre. Uma imagem ampliada. A dominação masculina. Trad. Maria Helena Kühner. Rio de Janeiro: Bertand Brasil, 2007.

DERRIDA, Jacques. A estrutura, o signo e o jogo no discurso das ciências humanas. A escritura e a diferença. Trad. Maria Beatriz da Silva. São Paulo: Perspectiva, 2002.

. A Farmácia de Platão. Trad. Rogério da Costa. São Paulo: Iluminuras, 2005.

FOUCAULT, Michel. 1967 - Nietzsche, Freud, Marx. In: MOTTA, Manoel Barros (org.). A arqueologia das Ciências e História dos Sistemas de Pensamento.Trad. Elisa Monteiro. Rio de Janeiro: Forense Universitária, 2005.

. A Ordem do discurso. Trad. Laura Sampaio.São Paulo: Loyola, 1998. (Leituras Filosóficas; 4). 
. As regularidades discursivas. A Arqueologia do Saber. Trad. Luiz Felipe Neves. Rio de Janeiro: Forense Universitária, 2000.

NIETZSCHE, Friedrich. Segunda Consideração Intempestiva; Da utilidade e desvantagem da história para a vida. Trad. Marcos Casanova. Rio de Janeiro: Relume Dumará, 2003. (Conexões; 20).

PADILHA, Maria Cavalcanti. Novas Fiandeiras das Palavras. Novos pactos, outras ficções; Ensaios sobre literaturas afro-luso-brasileiras. Porto Alegre: EDIPUCRS, 2002. (Coleção Memória das Letras; 10).

SANTOS, Boaventura Sousa. Onze teses por ocasião de mais uma descoberta de Portugal. Pela mão de Alice; O social e o político na Pós-modernidade. Porto: Afrontamento, 1994.

TAVARES, Ana Paula. Dizes-me coisas amargas como os frutos. Lisboa: Editorial Caminho, 2001.

\section{Eletrônicas:}

RIBEIRO, Maria Calafate. E outras vozes se alevantam - Ana Paula Tavares responde a Luís de Camões. Disponível em: www.scielo.oces.mctes.pt/pdf/aeq/n17/n17a08.pdf. Acesso em: 12 ago. 2009. TAVARES, Ana Paula. Entrevista a Cláudia Pastore. Disponível em: http://www.blocosonline.com.br/entrevista/pop artistas/ana paula.htm. Acesso em: 12 ago. 2009.

Title:

A Lesser Lyrics: For a Literary Theory of the African Literatures in Portuguese

\section{Abstract:}

The focusing on issues relating to the paradigms of the Literary Theory in those texts produced within a certain ethical-aesthetical context most often makes it impossible to understand the literary productions from outside the Eurocentric axis. As a disciplinary field, and due to the very building of its aesthetic criteria, Literary Theory tends to let aside the most recent literary production, mainly that from the emerging peripheries. By analyzing some poems by Ana Paula Tavares, a poet from Angola, the present essay will discuss the limits of the Literary Theory in face of the postcolonial literary production. 


\section{Key words:}

Theory of Lyrics, Angolan literature, Postcolonialism, Ana Paula Tavares

Recebido em 15.10.2010. Aprovado em 22.04.2010. 